\title{
BIOMASA DAN KANDUNGAN KARBON PADA HUTAN TANAMAN TUSAM (Pinus merkusii Jungh et de Vriese) UMUR LIMA TAHUN DI CIANTEN, BOGOR, JAWA BARAT (Biomass and Carbon Stock of Pine Plantation in Cianten, Bogor, West Java)
}

\author{
Oleh/By: \\ N. M. Heriyanto dan/and Chairil Anwar Siregar \\ Pusat Litbang Hutan dan Konservasi Alam \\ Jl. Gunung Batu No. 5 Po Box 165; Telp. 0251-633234, 7520067; Fax 0251-638111 Bogor \\ *) Diterima : 23 Mei 2006; Disetujui : 26 Maret 2007
}

\begin{abstract}
This study was designed to formulate pine allometric equations and estimate biomass production and carbon stock. Data collection was done in Resort Pemangkuan Hutan (RPH) Cianten, BKPH Leuwiliang, KPH Bogor, Perum Perhutani Unit III, West Java, from March to April 2005. This research employed destructive sampling method covering 23 representative trees (spacing $2 \mathrm{~m} \times 3 \mathrm{~m}$ ) located on 16 plots. Size of each plot was $20 \mathrm{~m} \times 30 \mathrm{~m}$. Results obtained from this research indicated that average oven dry matter of plant organ consisting stem, branch and twig, leaves, and roots were $6.04 \mathrm{~kg}, 3.15 \mathrm{~kg}, 3.36 \mathrm{~kg}$, and $1.78 \mathrm{~kg}$ respectively per plant at age of 5 years. The allometric equation expressing the relationship between above ground biomass and Dbh was $Y=0.17689 X^{2.0501}\left(R^{2}=0.9464\right)$, relationship between stem and Dbh was $Y$ $=0.11467 X^{1.9238}\left(R^{2}=0.9635\right)$, relationship between roots and Dbh was $Y=0.020346 X^{2.1291}\left(R^{2}=\right.$ 0.9163), and relationship between total biomass and Dbh was $Y=0.19687 X^{2.0611}\left(R^{2}=0.9472\right)$. The estimation results indicatds that the highest carbon stock originated from plant partition was produced from stem part (5.03 ton/ha), followed by leaves (2.8 ton/ha), branch and twig (2.62 ton/ha), and roots (1.48 ton/ha). The total carbon stock yield from 5 year old pine plantation was 11.93 to C/ha (equivalent to 43.74 ton $\mathrm{CO}_{2} / \mathrm{ha}$ ).
\end{abstract}

Key words : Biomass, carbon content, Pinus merkusii Jungh et de Vriese, allometry

\begin{abstract}
ABSTRAK
Penelitian ini bertujuan untuk mendapatkan persamaan alometri dan menduga kandungan karbon pada tegakan hutan tanaman tusam (Pinus merkusii Jungh et de Vriese) umur lima tahun. Penelitian dilakukan pada bulan Maret sampai April 2005 berlokasi di Resort Pemangkuan Hutan (RPH) Cianten, Bagian Kesatuan Pemangkuan Hutan (BKPH) Leuwiliang, Kesatuan Pemangkuan Hutan (KPH) Bogor, Perum Perhutani Unit III Jawa Barat. Pengumpulan data dilakukan dengan menggunakan metode destructive sampling melalui pemilihan pohon contoh, dari 16 plot berukuran $20 \mathrm{~m} \mathrm{x} 30 \mathrm{~m}$ dan dipilih 23 pohon yang dapat mewakili tegakan tusam. Hasil penelitian menunjukkan bahwa berat kering oven rata-rata bagian organ tanaman tusam yaitu bagian batang 6,04 kg, bagian daun 3,36 kg, bagian cabang dan ranting 3,15 kg, dan bagian akar 1,78 kg. Persamaan alometri hubungan antara berat kering bagian atas tanah tusam dengan diameter yaitu $\mathrm{Y}=0,17689 \mathrm{X}^{2,0501}\left(\mathrm{R}^{2}=0,9464\right)$, hubungan antara berat kering batang tusam dengan diameter yaitu $\mathrm{Y}=0,11467 \mathrm{X}^{1,9238}\left(\mathrm{R}^{2}=0,9635\right)$, hubungan antara berat kering akar tusam dengan diameter yaitu $\mathrm{Y}=0,020346 \mathrm{X}^{2,1291}\left(\mathrm{R}^{2}=0,9163\right)$, dan hubungan antara berat kering total tusam dengan diameter yaitu $\mathrm{Y}=0,19687 \mathrm{X}^{2,0611}\left(\mathrm{R}^{2}=0,9472\right)$. Kandungan karbon tusam paling tinggi diperoleh pada bagian batang yaitu sebanyak 5,03 ton/ha, kemudian berturut-turut bagian daun sebanyak 2,8 ton/ha, bagian cabang dan ranting 2,62 ton/ha, dan bagian akar sebanyak 1,48 ton/ha. Total kandungan karbon pada tegakan tusam umur lima tahun yaitu sebanyak 11,93 ton/ha atau setara dengan 43,74 ton $\mathrm{CO}_{2} /$ ha.
\end{abstract}

Kata kunci : Biomasa, kandungan karbon, Pinus merkusii Jungh et de Vriese, alometri 


\section{PENDAHULUAN}

Tusam merupakan salah satu spesies konifer yang penting, penghasil kayu bangunan, gondorukem, resin, dan terpentin. Selain itu kayu tusam merupakan material untuk pulp dan kertas yang berkualitas baik, karena berserat panjang. Pohon tusam tumbuh secara alami di Indonesia di daerah Aceh dan Kerinci pada ketinggian antara $800 \mathrm{~m}$ sampai $2.000 \mathrm{~m}$ di atas permukaan laut (Satjapradja, 1983). Menurut Sudiono et al. (1993), di Pulau Jawa terdapat 200.000 hektar tanaman tusam produktif. Pohon tusam tergolong pohon yang tumbuh cepat dan banyak menyerap karbon dari udara.

Hutan tropika banyak mengandung biomasa dan menyimpan karbon pada tanaman, baik yang hidup maupun yang sudah mati; demikian pula yang sukar lapuk dalam tanah maupun yang mudah lapuk (Whitmore, 1985).

Biomasa hutan dinyatakan dalam satuan berat kering oven per satuan luas, yang terdiri dari berat daun, bunga, buah, cabang, ranting, batang, akar serta pohon mati (Brown et al., 1989). Besarnya biomasa hutan tanaman ditentukan oleh umur tanaman, diameter, tinggi, kesuburan tanah, dan sistem silvikultur yang diterapkan. Pendugaan biomasa hutan tanaman tropis sangat diperlukan karena berpengaruh pada siklus karbon (Morikawa, 2002). Dari biomasa hutan, kurang lebih sebanyak antara 45 dan 50 persen adalah kandungan karbon (Brown et al., 1997; International Panel on Climate Change, 2003). Selanjutnya dinyatakan oleh Nelson et al. (1999), bahwa data biomasa suatu ekosistem sangat berguna untuk mengevaluasi pola produktivitas berbagai macam ekosistem yang ada. Tegakan hutan tanaman mempunyai potensi besar dalam menyerap dan mengurangi kadar karbondioksida di udara melalui kegiatan konservasi dan perbaikan manajemen tegakan hutan tanaman.

Penelitian ini bertujuan untuk memperoleh persamaan alometri untuk menduga kandungan karbon pada tegakan hutan tanaman tusam (Pinus merkusii Jungh et de Vriese) umur lima tahun, sehingga penentuan kandungan karbon selanjutnya cukup mengukur diameter saja tanpa harus menebang pohonnya. Hasil penelitian ini diharapkan dapat berguna untuk menduga kandungan karbon pada tegakan tusam, yang sekaligus memperkuat pengelolaan hutan.

\section{METODOLOGI}

\section{A. Deskripsi Lokasi dan Waktu Penelitian}

Penelitian ini dilakukan di Resort Polisi Hutan (RPH) Cianten, Bagian Kesatuan Pemangkuan Hutan (BKPH) Leuwiliang, Kesatuan Pemangkuan Hu$\tan (\mathrm{KPH})$ Bogor. Luas kawasan tanaman tusam di KPH Bogor yaitu seluas 22.914,69 ha.

Lokasi RPH Cianten mempunyai ketinggian tempat antara $800 \mathrm{~m}$ sampai $900 \mathrm{~m}$ dpl, iklimnya termasuk tipe A dengan curah hujan rata-rata $4.962 \mathrm{~mm}$ per tahun (Schmidt dan Ferguson, 1951). Secara geografis lokasi penelitian terletak pada koordinat $106^{\circ} 37^{\prime} 58^{\prime \prime}$ Bujur Timur dan 6 $6^{\circ} 44^{\prime} 25^{\prime \prime}$ Lintang Selatan. Keadaan topografi RPH Cianten secara umum berbukit-bukit, dengan kemiringan lahan antara $45 \%$ sampai $80 \%$. Penelitian dilakukan pada bulan Maret sampai April 2005.

\section{B. Bahan Penelitian}

Bahan penelitian adalah tegakan tusam berumur lima tahun dengan jarak tanam $2 \mathrm{~m} \times 3 \mathrm{~m}$. Plot dibuat sebanyak 16 buah pada empat blok, ukuran plot 10 $\mathrm{m} \times 10 \mathrm{~m}$. Semua tanaman dalam plot diukur diameter dan tinggi. Data ini kemudian menjadi dasar dalam menentukan jumlah pohon contoh yang akan diambil.

\section{Metode Penelitian}

1. Pemilihan pohon contoh. Setelah dilakukan sensus pohon, pohon yang 
dipilih berdasarkan distribusi diameter $(\mathrm{DBH})$ pada lokasi tersebut yaitu pohon dengan diameter terbesar dan terkecil yang menyebar merata. Untuk penelitian ini diperlukan 23 pohon contoh yang dapat mewakili tegakan tersebut.

2. Pengukuran tinggi dan diameter batang pohon. Setelah pohon ditebang, diameter batang diukur berturutturut pada posisi $0 \mathrm{~m}, 0,3 \mathrm{~m} ; 1,3 \mathrm{~m}$ (DBH); 3,3 m; 5,3 m; 7,3 m; 9,3 m; dan seterusnya setiap dua meter. Selain itu juga diukur diameter bebas cabang (Db).

3. Pengukuran berat basah pohon. Cabang dan ranting dipisahkan dari batang dan batang dipotong dalam bentuk log, di mana masing-masing log diberi nomor dan ditimbang. Cabang dan ranting yang hidup kemudian dipisahkan dari cabang dan ranting mati. Daun juga dipisahkan dari cabang dan ranting.

4. Contoh dipilih dan ditimbang untuk diukur berat kering dan kandungan karbonnya. Pengambilan contoh log dilakukan dari setiap bagian yaitu $\log 0 \mathrm{~m}-0,3 \mathrm{~m} ; 0,3 \mathrm{~m}-1,3 \mathrm{~m} ; 1,3 \mathrm{~m}-$ 3,3 m; 3,3 m-5,3 m; 5,3 m-7,3 m dan seterusnya; akar, cabang dan ranting hidup, cabang dan ranting mati serta daun, masing-masing sebanyak kurang lebih 200 gram.

5. Untuk mengetahui berat kering, contoh dimasukkan dalam kantung kertas dan dioven pada suhu $85^{\circ} \mathrm{C}$ selama 48 jam.

\section{Analisis Data}

Untuk mengetahui berat kering contoh digunakan rumus dari JICA (2002) sebagai berikut:

$\mathrm{BKT}=\frac{\mathrm{BKC}}{\mathrm{BBC}} \mathrm{X} \mathrm{BBT}$

Dimana :

BKT $=$ Berat kering total $(\mathrm{kg})$

BKC $=$ Berat kering contoh (gram)

$\mathrm{BBC}=$ Berat basah contoh (gram)

BBT $=$ Berat basah total $(\mathrm{kg})$
Kandungan karbon dalam tanaman, dihitung dengan menggunakan rumus :

Kandungan Karbon = Berat Kering Pohon x 50 \%

Pendugaan persamaan alometri dilakukan dengan menggunakan rumus :

$\mathbf{Y}=\mathbf{a} \mathbf{X}^{\mathbf{b}}$, dimana :

$\mathrm{Y}=$ Berat kering pohon

$\mathrm{X}=\mathrm{Dbh} /$ Diameter pohon setinggi dada $(1,3 \mathrm{~m})$

$\mathrm{a}, \mathrm{b}=$ Koefisien

\section{HASIL DAN PEMBAHASAN}

\section{A. Sebaran Kelas Diameter}

Pada empat plot berukuran $20 \mathrm{~m}$ x 30 $m$ di hutan tanaman dengan jarak tanam $2 \mathrm{~m} \times 3 \mathrm{~m}$, diambil pohon contoh sebanyak 23 pohon yang dapat mewakili tegakan tersebut. Sebaran kelas diameter pohon contoh tanaman tusam di RPH Cianten disajikan pada Tabel 1.

Dari Tabel 1 dapat dilihat bahwa tinggi bebas cabang rata-rata relatif rendah yaitu $1,53 \mathrm{~m}$. Hal ini dikarenakan dalam pengelolaan silvikultur tidak ada tindakan pemangkasan seperti pada umumnya untuk tujuan kayu produksi. Kerapatan tegakan pada lokasi ini sebesar 1.667 tanaman per hektar.

\section{B. Biomasa Tegakan}

Biomasa tegakan dapat dibedakan ke dalam dua kategori, yaitu biomasa di atas tanah (batang, cabang, ranting, daun, bunga, dan buah) dan biomasa di dalam tanah (akar). Kusmana et al. (1992) menyatakan bahwa besarnya biomasa ditentukan oleh diameter, tinggi pohon, berat jenis kayu, dan kesuburan tanah. Selanjutnya dinyatakan untuk menduga biomasa pada hutan pohon dapat digunakan parameter diameter dan tinggi pohon, akan tetapi diameter merupakan parameter yang paling akurat untuk menduga biomasa tegakan dibandingkan dengan tinggi pohon.

Diameter setinggi dada (DBH) pohon berkaitan erat dengan biomasa, di mana semakin besar diameter maka semakin besar biomasanya. Data berat kering, yang merupakan penduga biomasa pohon contoh disajikan pada Tabel 2. 
Tabel (Table) 1. Sebaran kelas diameter pohon contoh tusam berumur lima tahun di RPH Cianten, BKPH Leuwiliang, KPH Bogor (Class diameter distribution of five year old pine sample trees at RPH Cianten, BKPH Leuwiliang, KPH Bogor)

\begin{tabular}{ccccc}
\hline No. & $\begin{array}{c}\text { Diameter setinggi dada/ } \\
\text { Diameter at breast height }(1,3 \mathrm{~m}) \\
(\mathrm{cm})\end{array}$ & $\begin{array}{c}\text { Diameter bebas } \\
\text { cabang/Diameter at the } \\
\text { lowest branch }(\mathrm{cm})\end{array}$ & $\begin{array}{c}\text { Tinggi bebas } \\
\text { cabang/ Height of } \\
\text { free branch }(\mathrm{m})\end{array}$ & $\begin{array}{c}\text { Tinggi } \\
\text { total/Total } \\
\text { height }(\mathrm{m})\end{array}$ \\
\hline 1. & 1,9 & 3,9 & 0,44 & 2,35 \\
2. & 2,5 & 2,2 & 1,74 & 3,05 \\
3. & 2,9 & 2,8 & 1,59 & 2,98 \\
4. & 3,9 & 3,6 & 1,53 & 3,05 \\
5. & 5,4 & 4,9 & 1,94 & 4,47 \\
6. & 7,1 & 6,4 & 1,83 & 4,95 \\
7. & 8,1 & 7,7 & 1,64 & 5,30 \\
8. & 8,2 & 8,1 & 1,70 & 5,30 \\
9. & 8,3 & 7,8 & 1,60 & 6,05 \\
10. & 8,4 & 8,0 & 1,62 & 5,67 \\
11. & 8,5 & 7,9 & 1,52 & 5,75 \\
12. & 8,6 & 8,1 & 1,55 & 5,56 \\
13. & 8,7 & 8,0 & 1,54 & 6,00 \\
14. & 8,8 & 8,2 & 1,40 & 5,55 \\
15. & 8,9 & 8,4 & 1,50 & 6,82 \\
16. & 9,1 & 9,0 & 1,50 & 5,54 \\
17. & 9,2 & 8,5 & 1,55 & 6,17 \\
18. & 9,3 & 8,7 & 1,54 & 6,60 \\
19. & 9,4 & 9,2 & 1,38 & 6,60 \\
20. & 9,5 & 9,8 & 1,22 & 7,25 \\
21. & 9,6 & 9,1 & 1,45 & 6,17 \\
22. & 9,7 & 9,2 & 1,53 & 6,40 \\
23. & 11,0 & 10,5 & 1,86 & 6,38 \\
\hline
\end{tabular}

Tabel (Table) 2. Berat kering biomasa pohon contoh tusam di RPH Cianten, BKPH Leuwiliang, KPH Bogor (Dry biomass of pine sample trees at RPH Cianten, BKPH Leuwiliang, KPH Bogor)

\begin{tabular}{|c|c|c|c|c|c|c|}
\hline \multirow[b]{2}{*}{ No. } & \multirow[b]{2}{*}{$\begin{array}{l}\text { Diameter/Dbh } \\
\quad(\mathrm{cm})\end{array}$} & \multicolumn{4}{|c|}{ Biomasa/Biomass (kg) } & \multirow{2}{*}{$\begin{array}{c}\text { Berat total/ } \\
\text { Total dry weight } \\
\text { (kg) }\end{array}$} \\
\hline & & $\begin{array}{l}\text { Daun/ } \\
\text { Leave }\end{array}$ & $\begin{array}{c}\text { Cabang \& ranting/ } \\
\text { Branch \& twig }\end{array}$ & $\begin{array}{c}\text { Batang/ } \\
\text { Stem }\end{array}$ & $\begin{array}{c}\text { Akar/ } \\
\text { Root }\end{array}$ & \\
\hline 1. & 1,9 & 0,45 & 0,29 & 0,56 & 0,16 & 1,46 \\
\hline 2. & 2,5 & 0,24 & 0,12 & 0,52 & 0,11 & 0,99 \\
\hline 3. & 2,9 & 0,28 & 0,14 & 0,68 & 0,13 & 1,23 \\
\hline 4. & 3,9 & 0,75 & 0,26 & 1,33 & 0,27 & 2,61 \\
\hline 5. & 5,4 & 1,33 & 0,92 & 3,27 & 1,01 & 6,53 \\
\hline 6. & 7,1 & 2,20 & 1,57 & 5,25 & 0,96 & 9,98 \\
\hline 7. & 8,1 & 3,19 & 2,77 & 5,73 & 1,79 & 13,48 \\
\hline 8. & 8,2 & 3,74 & 2,25 & 6,14 & 1,45 & 13,58 \\
\hline 9. & 8,3 & 3,15 & 2,08 & 5,75 & 2,29 & 13,27 \\
\hline 10. & 8,4 & 3,74 & 2,53 & 7,14 & 1,97 & 15,38 \\
\hline 11. & 8,5 & 2,50 & 2,00 & 4,99 & 1,42 & 10,91 \\
\hline 12. & 8,6 & 4,94 & 4,33 & 6,72 & 2,42 & 18,41 \\
\hline 13. & 8,7 & 4,06 & 2,55 & 7,20 & 1,90 & 15,71 \\
\hline 14. & 8,8 & 3,93 & 3,71 & 5,80 & 1,66 & 15,10 \\
\hline 15. & 8,9 & 3,13 & 2,96 & 8,19 & 2,86 & 17,14 \\
\hline 16. & 9,1 & 3,62 & 3,02 & 7,20 & 1,58 & 15,42 \\
\hline 17. & 9,2 & 4,02 & 3,71 & 7,33 & 2,13 & 17,19 \\
\hline 18. & 9,3 & 4,54 & 3,39 & 10,47 & 1,83 & 20,23 \\
\hline 19. & 9,4 & 3,64 & 3,48 & 10,54 & 3,85 & 21,51 \\
\hline 20. & 9,5 & 5,73 & 6,12 & 8,01 & 2,26 & 22,12 \\
\hline 21. & 9,6 & 4,45 & 4,86 & 6,94 & 2,00 & 18,25 \\
\hline 22. & 9,7 & 4,74 & 5,54 & 9,22 & 3,50 & 23,00 \\
\hline 23. & 11,0 & 8,95 & 13,78 & 9,98 & 3,30 & 36,01 \\
\hline Rata & ta/Average & 3,36 & 3,15 & 6,04 & 1,78 & 14,33 \\
\hline
\end{tabular}


Dari Tabel 2 dapat dilihat adanya kecenderungan semakin besar diameter pohon maka semakin besar pula biomasa yang dimiliki oleh tanaman tersebut. Dari nilai rata-rata diketahui bahwa untuk tanaman tusam umur 5 tahun biomasa terbesar berada pada bagian batang $(6,04$ $\mathrm{kg}$ atau 42,15\%), disusul oleh daun (3,36 kg atau 23,45 \%), cabang dan ranting (3,15 kg atau 21,98 \%), dan akar $(1,78 \mathrm{~kg}$ atau $12,42 \%)$. Hal ini dapat dijelaskan bahwa biomasa berkaitan erat dengan proses fotosintesis, hasil dari fotosintesis tersebut digunakan oleh tumbuhan untuk melakukan pertumbuhan, baik ke arah vertikal (tinggi) maupun horizontal (diameter) dan sisanya disimpan dalam batang.

\section{Persamaan Alometri dan Kandungan Karbon Tegakan Tusam}

\section{Persamaan Alometri}

Pengukuran berat biomasa pohon hutan yang dilakukan dengan cara menebang seluruh pohon memerlukan waktu lama dan biaya yang besar. Untuk mempermudah diperlukan adanya persamaan alometri, yang berguna untuk menduga berat total biomasa tegakan. Setelah di-

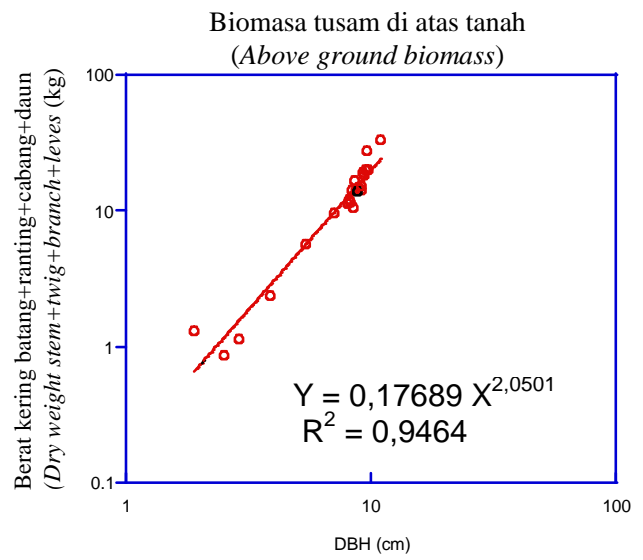

Gambar (Figure) 1. Grafik hubungan antara berat kering bagian atas tanah tusam dengan diameter, beserta persamaan alometrinya (Allometric equation of the relationship between above ground biomass and diameter at breast height) $(\mathrm{B} / \mathrm{W})$ temukan alometri maka berat biomasa tegakan dapat dihitung hanya dengan mengukur diameternya saja.

Berdasarkan 23 pohon contoh, dapat dibuat alometri untuk pohon tusam berumur lima tahun seperti terlihat pada Gambar 1 sampai Gambar 4.

Dari Gambar 1 sampai dengan Gambar 4, terlihat hubungan antara nilai biomasa pada tiap bagian tegakan tusam (akar, batang, bagian di atas tanah, dan total) dengan diameter. Nilai koefisien determinasi $\left(\mathrm{R}^{2}\right)$ untuk semua hubungan didapatkan di atas 0,9, yang berarti hubungan tersebut sangat erat. Dengan demikian untuk menduga biomasa tusam dapat dilakukan dengan cara mengukur diameter saja tanpa harus melakukan penebangan pohon (sampling destructive).

\section{Kandungan Karbon Tegakan Tusam}

Berdasarkan asumsi/rumus Brown et al. (1997) yang menyatakan bahwa $45 \%$ sampai $50 \%$ bahan kering pohon terdiri dari kandungan karbon, maka kandungan karbon pada bagian batang, cabang dan ranting, dan akar dalam tegakan tusam umur lima tahun (ton/ha) disajikan pada Gambar 5.

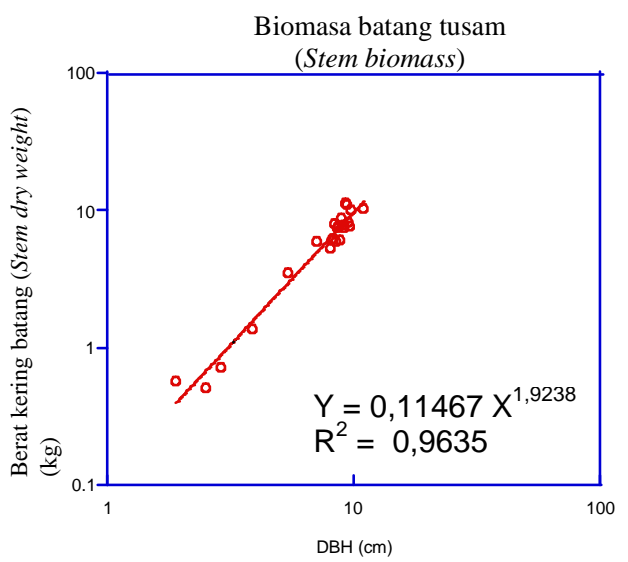

Gambar (Figure) 2. Grafik hubungan antara berat kering batang tusam dengan diameter, beserta persamaan alometrinya (Allometric equation of the relationship between dry weight stem and diameter at breast height) (B/W) 
Biomasa akar tusam (Root biomass)

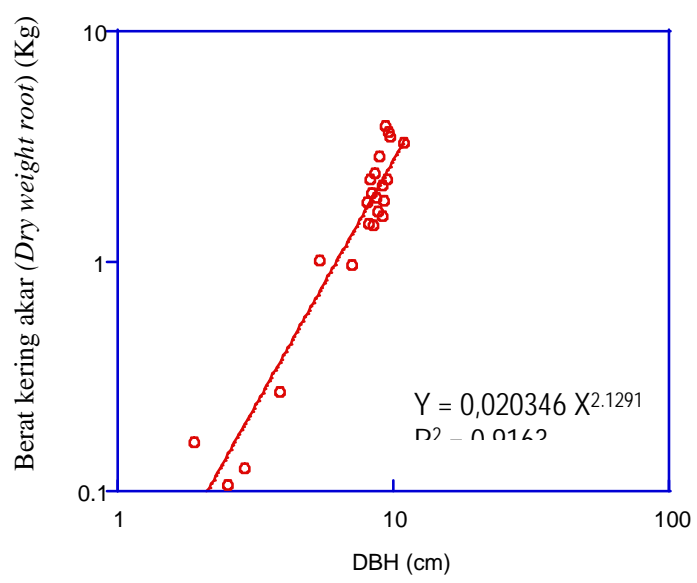

Gambar (Figure) 3. Grafik hubungan antara berat kering akar tusam dengan diameter, beserta persamaan alometrinya (Allometric equation of the relationship between dry weight root and diameter at breast height) $(\mathrm{B} / \mathrm{W})$

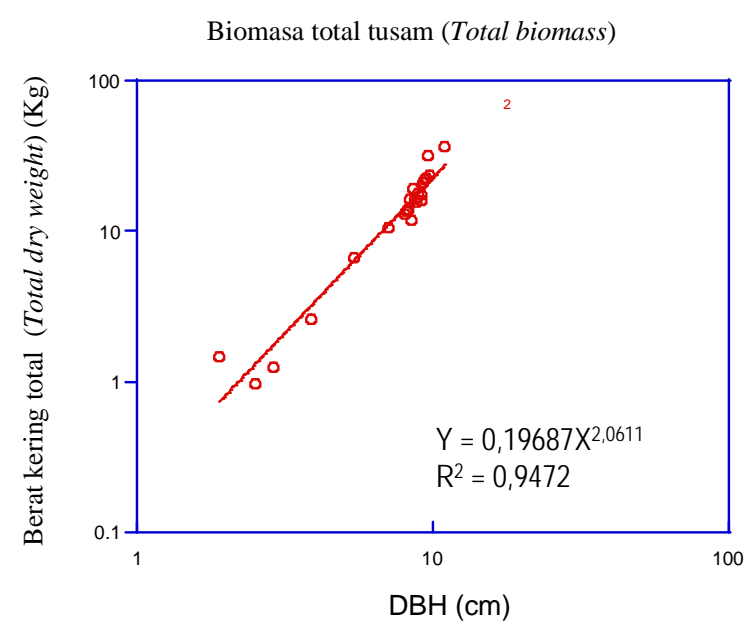

Gambar (Figure) 4. Grafik hubungan antara berat kering total tusam dengan diameter, beserta persamaan alometrinya (Allometric equation of the relationship between total dry weight and diameter at breast height) $(\mathrm{B} / \mathrm{W})$

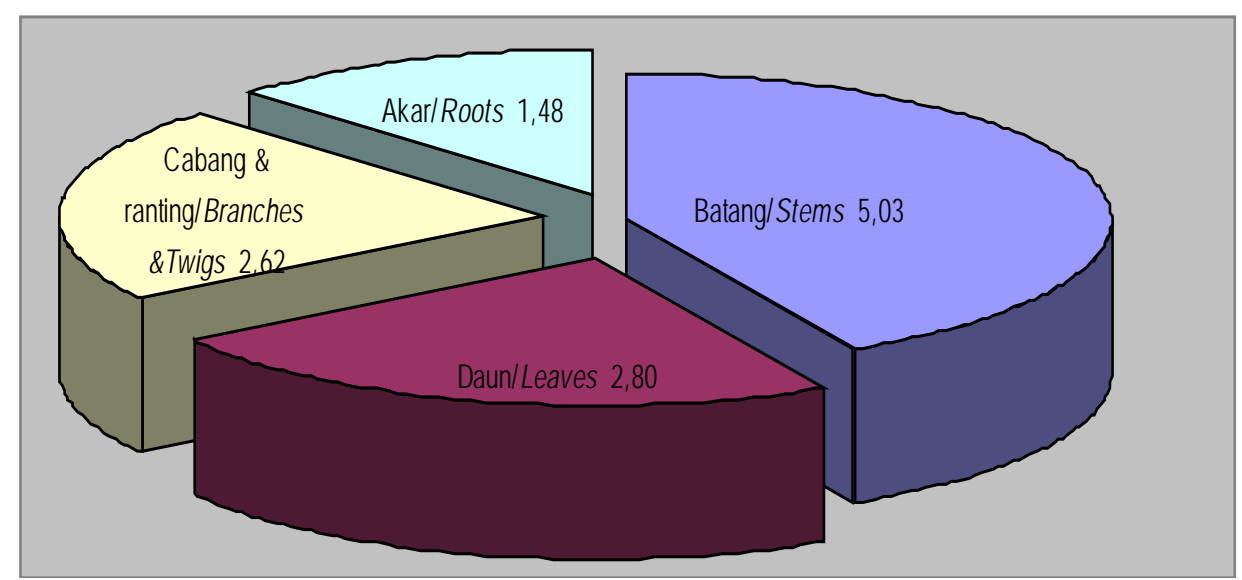

Gambar (Figure) 5. Kandungan karbon rata-rata bagian organ tusam umur lima tahun (Carbon stock average of plant organ of 5 year old pine) (ton/ha) (B/W)

Dari Gambar 5 dapat dikatakan bahwa kandungan karbon pada tegakan tusam umur lima tahun dengan kerapatan 1.667 pohon/ha, paling tinggi diperoleh dari bagian batang yaitu sebanyak 5,03 ton/ha, kemudian berturut-turut bagian daun sebanyak 2,8 ton/ha, bagian cabang dan ranting 2,62 ton/ha, dan bagian akar sebanyak 1,48 ton/ha. Total kandungan karbon pada tegakan tusam umur lima tahun yaitu sebanyak 11,93 ton/ha atau setara dengan 43,74 ton $\mathrm{CO}_{2} /$ ha.

\section{KESIMPULAN DAN SARAN}

\section{A. Kesimpulan}

1. Berat kering oven rata-rata bagian organ pohon tusam berturut-turut yaitu bagian batang 6,04 kg, bagian daun $3,36 \mathrm{~kg}$, bagian cabang dan ranting $3,15 \mathrm{~kg}$, dan bagian akar $1,78 \mathrm{~kg}$.

2. Persamaan alometri antara berat kering bagian atas tanah tusam dengan diameter ialah $\mathrm{Y}=0,17689$ $\mathrm{X}^{2,0501} \quad\left(\mathrm{R}^{2}=0,9464\right)$, antara berat 
kering batang tusam dengan diameter ialah $\mathrm{Y}=0,11467 \quad \mathrm{X}^{1,9238} \quad\left(\mathrm{R}^{2}=\right.$ 0,9635), antara berat kering akar tusam dengan diameter ialah $\mathrm{Y}=$ $0,020346 \mathrm{X}^{2.1291} \quad\left(\mathrm{R}^{2}=0,9163\right)$, dan antara berat kering total tusam dengan diameter ialah $\mathrm{Y}=0,19687 \mathrm{X}^{2,0611}$ $\left(\mathrm{R}^{2}=0,9472\right)$.

3. Kandungan karbon tusam paling tinggi diperoleh pada bagian batang yaitu sebanyak 5,03 ton/ha, kemudian berturut-turut bagian daun sebanyak 2,8 ton/ha, bagian cabang dan ranting 2,62 ton/ha, dan bagian akar sebanyak 1,48 ton/ha. Total kandungan karbon pada tegakan tusam umur lima tahun yaitu sebanyak 11,93 ton/ha.

\section{B. Saran}

Untuk mengetahui kandungan karbon pada suatu tegakan, selain diukur jenis pohon yang dominan sebagai tanaman pokok juga perlu diukur kandungan karbon tumbuhan bawahnya.

\section{DAFTAR PUSTAKA}

Brown, S., A.J.R. Gillespie and A.E. Lugo. 1989. Biomass Estimation Methods for Tropical Forest with Applications to Forest Inventory Data. Forest Science 35 : 881-902.

Brown, S. 1997. Estimating Biomass and Biomass Change of Tropical Forest. A Primer, FAO. Forestry Paper No. 134. FAO, USA.

International Panel on Climate Change. 2003. IPPC Guidelines for Nation Greenhouse Inventories : Reference Manual IPCC.

JICA. 2002. Demonstration Study on Carbon Fixing Forest Management
Project. Progress Report of The Project 2001-2002.

Kusmana, C., S. Sabiham, K. Abe and H. Watanabe. 1992. An Estimation of Above Ground Tree Biomass of A Mangrove Forest in East Sumatera. Tropics I (4) : 143-257.

Morikawa, Y. 2002. Biomass Measurement in Planted Forest in and Around Benakat. Fiscal Report of Assessment on The Potentiality of Reforestation and Afforestation Activities in Mitigating The Climate Change 2001, 58-63. JIFPRO, Tokyo, Japan.

Nelson, B.W., R. Mesquita, J.L.G. Periera, S.G.A. de Souza, G.T. Batista and L. B. Couto. 1999. Allometric Regressions for Improved Estimate of Secondary Forest Biomass in The Central Amazon. Forest Ecology and Management 117 : 149-167.

Satjapradja, O. 1983. Evaluasi Lahan Tegakan Pinus merkusii. Makalah Penunjang Simposium Hutan Pinus.

Schmidt, F.H and J.H. Ferguson. 1951. Rainfall Types Based on Wet and Dry Period Ratios for Indonesia with Western New Guinea. Verhand. No. 42. Kementerian Perhubungan Djawatan Meteorologi dan Geofisika. Jakarta.

Sudiono, J., K. Soemarna dan A. Suharlan. 1993. Tabel Tegakan Sepuluh Jenis Kayu Industri. Pusat Penelitian dan Pengembangan Hutan dan Konservasi Alam. Badan Penelitian dan Pengembangan Kehutanan. Departemen Kehutanan. Bogor.

Whitmore, T.C. 1985. Tropical Raint Forest of The Far East. Oxford University Press, New York. 